\title{
O contexto contemporâneo da administração pública na América Latina ${ }^{1}$
}

Caio Marini

\section{A reforma gerencial no contexto da transformação do Estado contemporâneo}

A crise dos anos 70, que provocou iniciativas de reestruturação econômica e a reconfiguração das estratégias empresariais, introduziu, já no início dos anos 80, no debate sobre o Estado contemporâneo, questões relativas às necessidades de incorporação de novos papéis, de abandono de outros e, sobretudo, a exigência de reorganização para enfrentar a crise e adequar-se aos novos requerimentos. Essa crise, em que pese a preponderância da dimensão financeira, coloca em questionamento o modo tradicional de organização e gestão governamental, a partir do esgotamento do modelo burocrático de administração pública vigente. Como consequiência, isso vem produzindo um profundo déficit de desempenho em termos da baixa qualidade na prestação dos serviços ao cidadão, que é a dimensão da crise percebida pelo cidadão. Inicialmente na Grã-Bretanha, e depois adotada, quase que de forma generalizada, em diversos outros países, a estratégia de enfrentamento ficou conhecida como a New Public Management (Nova Gestão Pública - NGP).

Assim, o desafio de promover as mudanças necessárias impõe ao Estado a necessidade de repensar a questão da governança e dos modelos de gestão, ao mesmo tempo em que vai exigir mecanismos inovadores de relacionamento com a sociedade. A emergência do terceiro setor e dos movimentos sociais, além dos movimentos que têm como base o voluntariado, vem introduzindo elementos desafiadores nessa nova configuração em rede que caracteriza o Estado contemporâneo. O objetivo é comum e trata, fundamentalmente, de encontrar alternativas para superar as

Caio Marini é assessor da direção do Serpro e professor colaborador na FGV, ENAP e ESAF.

Contato: caio.marini@ serpro.gov.br 
desigualdades, ampliando o espaço de inclusão na vida social, política e econômica na direção do desenvolvimento, a partir da internalização/fortalecimento dos conceitos de cidadania, eqüidade e transparência, além da temática própria da gestão contemporânea, que supõe maior eficiência e qualidade no tratamento do interesse público. Isso, seguramente, força a adoção de enfoques não convencionais na construção de estratégias para enfrentar a crise, o que implica o fortalecimento de mecanismos de interação Estado/sociedade. Isoladamente, as forças direcionadas para a mudança perdem vitalidade e objetividade. Portanto, é necessário consolidar alianças que assegurem sinergia, a partir da ampliação da consciência de cidadania e da construção de soluções criativas e inovadoras que garantam legitimidade e viabilidade às transformações reclamadas pela sociedade.

A realidade latino-americana não é distinta da descrição feita anteriormente. Nesse contexto, o Conselho Diretor do Centro LatinoAmericano de Administração para o Desenvolvimento (CLAD) aprovou um documento (1998), que estabeleceu as bases da reforma gerencial na região. Nele são destacadas as especificidades próprias da América Latina, basicamente as relativas à gravidade da crise do Estado, muito maior que a existente no mundo desenvolvido. $\mathrm{O}$ documento aponta a necessidade de direcionar a estratégia da reforma na região, considerando três questões essenciais: a consolidação da democracia, a retomada do crescimento econômico e a redução da desigualdade social. Também, enuncia o objetivo central da reforma gerencial, que é o de assegurar os mecanismos necessários para o aumento da eficácia, eficiência e efetividade da administração pública, além de criar novas condições que possibilitem uma relação mais democrática entre Estado e sociedade. Finalmente, são destacados os princípios básicos que deverão orientar a implementação desse novo modelo administrativo, com destaque para:

- a profissionalização da alta burocracia, visando ao fortalecimento das capacidades de formulação e à avaliação de políticas públicas;

- a focalização no atendimento das demandas do cliente-cidadão;

- a transparência e responsabilização democrática na administração pública;

- a descentralização da execução dos serviços aos níveis subnacionais;

- a desconcentração organizacional da execução de funções do governo central para agências especializadas;

- a orientação dos mecanismos de controle para resultados, baseados em indicadores fixados em contratos de gestão; e

- a adoção de um novo desenho organizacional para as atividades não exclusivas (formuladas, reguladas e financiadas pelo Estado, mas executadas pelo setor público não estatal). 


\section{Em busca das melhores práticas a partir do exame de algumas experiências nacionais selecionadas ${ }^{2}$}

\section{Preâmbulo}

Uma das principais tendências da gestão contemporânea, na perspectiva do desenvolvimento organizacional, tem sido o intercâmbio de experiências institucionais a partir da disseminação das melhores práticas. A partir dos anos 80, as empresas passaram a adotar, freqüentemente, processos de análise comparativa, visando ao aperfeiçoamento de seus modelos de gestão e tomando como referência aquelas práticas tidas como mais avançadas. Esse processo, que foi inicialmente utilizado no setor privado pela Xerox Corporation, passou a ser denominado de benchmarking. Atualmente, vem sendo usado em larga escala pelas organizações do setor público, notadamente a partir do advento da reforma gerencial. As experiências do Reino Unido, da Austrália e da Nova Zelândia - tidas como referências nesse campo — têm sido recomendadas pelos organismos internacionais e, como consequiência, vêm impactando as iniciativas recentes de reforma na região. Naturalmente, o bom senso recomenda prudência nesse esforço de análise comparativa - cada caso é um caso. Assim, abrir-se para o conhecimento e intercâmbio de experiência é sempre saudável, mas, no momento da decisão sobre a estratégia de reforma a ser adotada, cada país deve levar em consideração suas próprias peculiaridades e os elementos de seu contexto social, econômico e cultural. A esse respeito, vale a pena examinar as recomendações de Ramió (2001) sobre os problemas de implementação da NGP em países latinos, em função dos modelos de Estado e da cultura institucional dominantes.

O exame da experiência recente na região, infelizmente, é pouco conclusivo e, contraditoriamente ao princípio da NGP, que destaca a orientação a resultados, não permite aferições mais precisas sobre a efetividade dos programas de reforma gerencial. Os balanços tendem a produzir mais registros de iniciativas do que avaliação de impactos dos programas (este artigo não é uma exceção à regra dominante). Contudo, o exame das iniciativas realizadas indica uma trajetória, quase um padrão, em que é possível identificar alguns elementos comuns nas estratégias adotadas, que dão especificidade ao conjunto de iniciativas que vêm sendo implementadas, como, por exemplo:

a) fortalecimento de canais de relacionamento Estado/sociedade a partir de iniciativas orientadas para a melhoria da qualidade na formulação das políticas públicas; busca de maior participação cidadã; introdução de mecanismos de controle social; melhoria na entrega de serviços públicos e maior envolvimento do terceiro setor; 
b) aperfeiçoamento do marco legal, visando à eliminação de entraves de natureza burocrática, que impedem a adoção de modelos de gestão orientados a resultados com maior flexibilidade e autonomia;

c) recuperação da capacidade financeira (racionalismo econômico), a partir de iniciativas voltadas para a melhoria da eficiência, e introdução da cultura da responsabilidade fiscal;

d) desenvolvimento das capacidades institucionais dos órgãos da administração pública, incluindo o fortalecimento do planejamento estratégico como ferramenta de gestão, programas de reestruturação administrativa, mecanismos de contratualização, intensificação do uso da tecnologia da informação e a terceirização de serviços de apoio; e

e) desenvolvimento do capital intelectual, a partir de iniciativas voltadas para a profissionalização e modernização do serviço civil, intensificação de programas de capacitação de servidores e de lideranças, ética na administração pública, adoção de mecanismos inovadores de remuneração de funcionários e introdução da gestão do conhecimento.

A seguir, serão apresentados relatos de algumas experiências nacionais recentes no contexto do movimento de reforma gerencial na América Latina.

\section{A experiência do Uruguai}

A experiência recente de reforma do Estado no Uruguai começou em 1995, compreendendo iniciativas que visavam promover transformações nos segmentos da seguridade social, educação, sistema político, cidadania e administração pública. Neste último campo, as mudanças foram graduais e persistentes e tiveram no orçamento seu principal instrumento de legitimação.

Os objetivos da reforma, segundo Cobas (1998):

"partiram de um trabalho para redefinir que Estado Uruguaio seria requerido para atender às prioridades estratégicas do país em consonância com as políticas e equilíbrios macroeconômicos supondo uma adequação organizacional para a busca da eficiência para melhorar a performance e, em última instância, o nível de vida da população".

As principais ações estavam orientadas para as áreas de reformulação das estruturas organizacionais, introdução da gestão por resultados, melhoria do atendimento ao usuário, compras governamentais, capacitação de funcionários e gestão das regulações. A expectativa era que, ao final do programa, a administração pública uruguaia estivesse funcionando em perspectiva mais gerencial, com base em resultados e com foco na satisfação das necessidades do cidadão e na qualidade dos serviços públicos. 
Nesse sentido, foi constituído o Comitê Executivo para a Reforma do Estado (Cepre) no âmbito da Oficina de Planeamiento y Presupuesto (criado pela Lei do Orçamento Nacional de janeiro de 1996), com a finalidade de implantar e dar continuidade ao Programa de Modernização do Estado, assim como verificar o cumprimento das metas fixadas. O comitê, presidido pelo diretor da Oficina de Planeamiento y Presupuesto, estava integrado por representantes designados pelo ministro da Economia e Finanças e pelo diretor da Oficina Nacional de Servicio Civil. O programa tinha os seguintes objetivos básicos:

- melhorar a eficiência, a eficácia e o impacto do gasto público, a partir da execução do gasto por centro de atividade, o que permitirá melhor conhecimento dos custos e construção de indicadores de gestão, visando ao aperfeiçoamento dos processos orçamentários futuros;

- obter maior transparência, maior competitividade e eficiência nas aquisições públicas, aproveitando as vantagens decorrentes do poder de compras do Estado, usando portal que permita disponibilizar, online, as demandas do Estado para ofertas do setor privado;

- disponibilizar informações sobre rendimentos dos funcionários públicos no site do governo, visando a maior transparência;

- aperfeiçoar as condições objetivas de trabalho, por meio da disponibilização de informações sobre horas trabalhadas dos funcionários da administração central;

- implantar a administração eletrônica usando a tecnologia de Portal (porta de entrada para todos os sites governamentais com informações sobre serviços e trâmites e sobre gestão pública, além de canal de comunicação interna entre os órgãos governamentais e entre o Estado, os cidadãos e as empresas); e

- desregulamentar por intermédio da implementação de mudanças, visando à redução de custos e à eliminação de restrições desnecessárias para cidadãos e empresas.

A estratégia da reforma, segundo Cobas (1998), não foi concebida a partir da simples idéia de redução do tamanho do Estado, mas fundamentalmente baseada no princípio da realocação setorial, implicando, inclusive, o aumento do orçamento de algumas áreas sociais. Os principais resultados da reforma, ainda segundo Cobas, indicam avanços importantes na direção do fortalecimento das relações entre o Estado e o mercado, visando à redução de monopólios, provocando na administração pública algumas mudanças relevantes:

- atividades não substantivas passaram a ser desenvolvidas pelo mercado, de acordo com os marcos regulatórios respectivos;

- supressão de duplicidades e definição de formas mais autônomas de prestação de serviços; e 
- reestruturação dos postos de trabalho com sua redução de aproximadamente $30 \%$ e, ao mesmo tempo, a criação de novos postos de trabalho com maior produtividade (13\%).

A experiência de reforma no Uruguai teve um caráter inovador, na visão de Berretta (2000). Em primeiro lugar, buscou-se articular as medidas de reforma da administração pública e as de modernização da gestão. $\mathrm{Na}$ primeira fase, foram realizadas iniciativas de reestruturação administrativa e declarados os cargos e funções excedentes, o que acabou gerando um programa de realocação para os funcionários destituídos. Na segunda fase, foram desenvolvidos programas orientados para a melhoria da eficiência e da gestão com foco no cidadão. Outra iniciativa exitosa foi a reformulação das unidades executoras, que passaram a contar com uma clara definição de missão institucional e respectivos encargos decorrentes (classificados como: substantivos, de apoio aos substantivos e não-substantivos). Também, a autora destaca as importantes mudanças realizadas nas formas de prestação dos serviços públicos, que forçaram a focalização dos ministérios nas suas atividades substantivas, permitindo a terceirização das atividades de apoio, preferencialmente, a empresas formadas por ex-funcionários. E, finalmente, as mudanças na gestão de recursos humanos permitiram, via lei orçamentária, que parte das economias geradas fosse aplicada para corrigir os desvios de remuneração nas estruturas aprovadas, além de financiar o sistema de alta gerência.

\section{A experiência do Chile}

Embora existam semelhanças, o cenário em que se processa a reforma do Estado chileno apresenta, pelo menos, uma importante diferença em relação aos demais países da região. O Chile é, provavelmente, a única exceção à regra geral dominante, caracterizada por programas de reformas orientados para o enfrentamento dos problemas decorrentes da crise financeira do Estado. O grande desafio colocado é o de manter o equilíbrio fiscal obtido. Bresser Pereira (2002) comenta que:

“... desde 1982 o Chile não enfrenta alguns dos problemas que ocorrem geralmente nos processos de reforma do Estado, tais como a crise fiscal, corrupção difundida, ineficiências evidentes ou questionamentos sérios sobre o tamanho ou escopo apropriados do Estado".

Além disso, segundo Shepherd (1988), o chile foi o país que mais avançou na reforma gerencial na região:

"desde o início dos anos 90, a administração pública chilena

tem adotado uma diversidade progressivamente mais ampla de 
instrumentos da Nova Gestão Pública, entre eles o Planejamento Estratégico, acordos de modernização, remuneração baseada em desempenho, indicadores de performance e avaliação de programas do setor público".

Orrego (1998) destaca os fatores que pressionaram as mudanças nos anos 90: a dívida social dos anos 80, o aumento das demandas sociais produzidas pelo novo contexto democrático, a necessidade de melhoria da qualidade dos serviços e os novos temas da agenda pública, como meio ambiente e desenvolvimento urbano. Neste contexto, as reformas foram concebidas a partir de quatro dimensões básicas:

- econômica: orientada a fortalecer a capacidade reguladora do Estado, a partir dos processos de privatização;

- política: caracterizada pela transição de um Estado autoritário e centralizador para um Estado democrático, participativo e descentralizado;

- social: a partir de mudanças de um modelo frágil de provimento direto dos serviços sociais para um novo modelo que compartilhe essas funções com o mercado e o terceiro setor; e

- gestão: orientada para a introdução de uma nova gerência pública, baseada na qualidade e em resultados, em substituição a uma burocracia formalista, baseada somente na norma.

Em continuidade ao processo de mudanças contemporâneas, o atual governo chileno adotou, como eixo central de seu projeto de reforma e modernização, "o Estado a serviço da cidadania", compreendendo duas linhas básicas de ação: a primeira refere-se às transformações na estrutura do setor público e a segunda centra-se propriamente na gestão, com ênfase na construção de nova institucionalidade, baseada no redesenho do aparelho do Estado, na descentralização administrativa, na modernização da gestão pública, com inovações na área de recursos humanos, e na qualidade de serviços (portal de trâmites, carta de direitos do cidadão, prêmio de qualidade) e, por último, o programa de governo eletrônico, incluindo o estabelecimento de novas formas de atendimento ao público, melhoria da gestão interna do governo e o desenvolvimento da democracia, a partir da introdução de novos mecanismos de participação cidadã.

Finalmente, vale destacar que as principais iniciativas em fase de implantação são as seguintes (Orrego, 1998):

- Sistema de Gestão Estratégica Governamental, incluindo a definição de metas ministeriais (desde 1990), acordos de desempenho com base em indicadores (desde 1992), com destinação de parte dos ganhos aos funcionários, e implantação dos balanços integrais de gestão, que obriga a prestação de contas de todas as realizações nos âmbitos financeiros e de gestão;

- mudança cultural e de liderança dos gerentes públicos, a partir do estímulo a iniciativas expontâneas de modernização (posteriormente 
expandidas a toda a administração pública), além de investimentos na formação e qualificação dos funcionários;

- Avaliação Pública dos Programas de Estado, a partir de painéis conduzidos por especialistas externos, que prestam contas sobre a pertinência, validade e eficácia dos programas governamentais (desde 1997);

- Programa de Qualidade, com o objetivo de instaurar, no âmbito da administração pública, a cultura da qualidade, incluindo a criação do Prêmio Nacional da Qualidade (desde1997); e

- Sistema de Informação e Compras Eletrônicas, que dá transparência a todos os processos licitatórios (desde 1999) e encaminha-se para a efetivação de todas as transações por via eletrônica.

\section{A experiência do Peru}

O processo de modernização do Estado tem como premissas fundamentais a busca da melhoria da gestão pública e a construção de um Estado democrático, descentralizado e a serviço do cidadão.

Além da Comisión de Promoción de la Inversión Privada (Copri), que cumpre as funções de gerenciar o programa de promoção do investimento privado por meio de processos de privatização e de concessões de infra-estrutura e serviços públicos, foi atribuída à Presidência do Conselho de Ministros (PCM), entre outras, as funções de promover a melhoria da gestão pública, a qualidade do gasto, o aperfeiçoamento da organização das entidades públicas e a eficiência dos processos e sistemas administrativos. Subordina-se a essa presidência uma Direccion General de Gestion Pública. Ainda do ponto de vista institucional, merece destaque a criação da Comissão de Modernização da Gestão do Estado no âmbito do Congresso da República, com a finalidade de contribuir para o fortalecimento das instituições do país, e a criação de um Estado moderno e a serviço das pessoas. Shepherd (1998) destaca da experiência recente as iniciativas de reforma da administração tributária e aduaneira, a regulamentação da concorrência, a proteção do consumidor e o provimento de serviços públicos por meio de organismos autônomos.

O processo de modernização estabeleceu como objetivos: a melhoria da prestação de serviços, a criação de canais de participação cidadã, a descentralização e desconcentração, uma gestão pública transparente e com equilíbrio fiscal e a qualificação dos servidores. Além de iniciativas específicas, relacionadas a esses objetivos, algumas ações complementares visando ao aperfeiçoamento dos dispositivos de natureza legal estão em desenvolvimento (Lei do Poder Executivo, Lei Orgânica do Sistema Nacional de Controle e Controladoria Geral, Lei de Carreira Pública e leis orgânicas de diversos organismos do Estado). Como estratégia de implementação do processo de modernização estão sendo adotados 
programas-piloto, inicialmente na PCM e, em seguida, em outros ministérios selecionados por meio de convênios de gestão orientados para a utilização de modernas práticas de gerenciamento. Além disso, visando aumentar a eficiência no uso dos recursos públicos, estão sendo implementadas iniciativas de aperfeiçoamento e integração do planejamento estratégico, elaboração orçamentária e controle da execução do orçamento. Finalmente, vale mencionar a criação de um portal do Estado peruano, que permite o acesso às informações e consultas sobre as diversas instituições estatais, finanças públicas, oportunidades de negócios para investidores, legislação, compras governamentais e, mais recentemente, sobre o projeto de governo eletrônico.

\section{A experiência da Nicarágua}

O contexto que antecedeu a experiência recente de reforma do Estado foi marcado pelos esforços de transformar a economia nicaraguense em economia social de mercado, capaz de permitir o desenvolvimento sustentável, restaurar a paz e construir a democracia, a partir do governo eleito em 1990, que encontrou o país submergido em profunda crise estrutural: queda das exportações, hiperinflação, infra-estrutura destruída, escassez de recursos humanos qualificados, elevada dívida externa, sistema monetário deteriorado, sociedade dividida, setor privado pequeno e excessivamente regulado e um setor público superdimensionado, deficitário, ineficiente e altamente centralizado. Em um primeiro momento, foi instituído um programa de estabilização macroeconômica e ajuste estrutural — Fundo Monetário Internacional (FMI) e Banco Mundial — que produziu, como resultados, a eliminação da hiperinflação, a estabilização de preços, a liberalização de mercados, a flexibilização de monopólios, a reorganização do setor bancário, o saneamento das finanças públicas e a descentralização administrativa, o que permitiu recuperar parte da credibilidade internacional.

Em 1994, em que pese os avanços obtidos, era ainda necessário prosseguir nos esforços de aprofundamento de reformas estruturais. Nesse sentido, foi criado o Comitê Executivo para a Reforma da Administração Pública (Cerap), com a atribuição de implementar um programa de reforma e modernização do setor público, visando a criação de uma administração pública moderna, pequena, forte, eficiente e facilitadora. O Cerap conta com uma Secretaria Executiva e uma Unidade de Coordenação que funciona como instância técnica do programa.

A primeira etapa do programa (1994/1996) consistiu na realização de um diagnóstico orgânico-funcional global das instituições do Poder Executivo, que identificou a ausência de objetivos, o superdimensionamento, a justaposição de funções, a fragmentação de responsabilidades, a falta de base legal na contratação de pessoal, a inexistência de um sistema de 
gestão de recursos humanos, a ineficiência e a falta de transparência e controle na gestão financeira. Na segunda etapa (1996/1999), avançou-se na atualização do diagnóstico, incluindo análises setoriais e a elaboração de estratégia de reforma baseada em gestão por processos, que foi implementada via mecanismos de contratualização interna - Acordos de Reestruturação Institucional (ARI) entre o Cerap e as diversas entidades. Também foram estabelecidos projetos de reestruturação do serviço civil e gestão financeira (sistema informatizado de gestão integrada). A etapa atual consiste na focalização do programa na gestão econômica e consolidação das iniciativas anteriores. Como resultados obtidos até o momento, destacam-se: a institucionalização do programa de reforma, o desenvolvimento de uma ampla base de conhecimento e informação sobre a administração pública, a celebração de sete ARIs, o redesenho de processos com $40 \%$ de redução de custos, a modernização da legislação administrativa, a capacitação de mais de 600 funcionários e a elaboração de catálogos de serviços e trâmites do Poder Executivo.

\section{A experiência da Argentina}

A crise do Estado é um fenômeno global, que tem apresentado características bastante semelhantes em diversas realidades e alto grau de interdependência internacional. Mas, sem dúvida, o caso argentino, em que pese a influência desse contexto mundial de crise, tem suas próprias singularidades, que vão desde aspectos ligados à baixa governabilidade (legitimidade para proceder aos ajustes necessários) até questões relativas à capacidade do aparato estatal (governança) para enfrentar o contexto dramaticamente adverso dos dias atuais.

A experiência recente de reforma começou em 1983, ocasião da retomada do processo de redemocratização do país, com a criação da Secretaria da Função Pública, que incorporou o Instituto Nacional de Administración Pública (INAP), estabelecendo como prioridade a necessidade do fortalecimento das carreiras administrativas, e adotou, como uma das primeiras iniciativas, a instituição do corpo de altos administradores, inspirado na experiência francesa. As primeiras turmas foram formadas, mas, a partir de 1987, a iniciativa foi descontinuada.

A partir de 1989, inicia-se um novo ciclo na vida política argentina, com importantes implicações do ponto de vista da reforma do Estado e, em particular, da administração pública. Ghio (2000) cita duas etapas principais:

- 1a etapa (1989-1994): caracterizada pela ênfase na erradicação do déficit fiscal, tinha como uma das estratégias centrais a planificação do aparato estatal, orientada para a melhoria da eficiência — Estado menor, 
porém mais forte, com estruturas simples, evitando superposições. Nesse período (1990), foi criado o Comité Controlador de la Reforma Administrativa (Cecra), impondo como estratégia dominante o downsizing, fundamentada em uma escalada de decretos, determinando redução das estruturas administrativas e disponibilidade de pessoal; e

- 2a etapa (1994-1999): marcada, inicialmente, pela promulgação da nova Constituição nacional que permitiu a criação de novos organismos, tais como o Ministério Público, o instituto contra a discriminação e a Auditoria Geral da Nação. O decreto de 1996 cria a Unidad de Reforma y de Modernizacion del Estado no âmbito do Gabinete de Ministros, com a missão de elaborar um Programa de Modernização do Estado. A estratégia dominante no período estava caracterizada pela fusão de diversos órgãos da administração pública, pelo fortalecimento das entidades de arrecadação e por políticas de fortalecimento institucional e melhoria das capacidades administrativas.

Não obstante, essas iniciativas, avaliações recentes continuam apontando o agravamento de problemas, tais como a provisão insuficiente de serviços, a baixa qualidade na prestação deles e o desempenho deficiente em seu papel regulador, colocando em xeque o modelo de gestão pública vigente, tido como moroso e excessivamente orientado para as rotinas. Assim, a Subsecretaria de Gestão Pública, criada em 1999, em substituição à Secretaria da Função Pública, está desenvolvendo um Plano Nacional de Modernização do Estado, visando à implementação de moderno sistema de gerência pública para os organismos da administração nacional. As principais linhas de abordagem do Plano são as seguintes:

- transformações institucionais, que apontam para a otimização da gestão das organizações estatais, levando em consideração as características particulares de cada uma. As mudanças têm como objetivos incrementar a produtividade e melhorar a qualidade dos serviços prestados pelo setor público. As principais iniciativas são a carta-compromisso com o cidadão e a gestão por resultados; e

- transformações horizontais, que apontam para a mudança nos sistemas que cortam transversalmente toda a administração nacional em suas modalidades de gestão. As ações prioritárias estão focalizadas no desenvolvimento do capital humano, modernização dos sistemas administrativos (compras e finanças) e implementação do governo eletrônico.

Dentre as principais iniciativas no campo da modernização da gestão, merece destaque a criação do Prêmio Nacional de Qualidade, que vem premiando as experiências exitosas na administração pública desde 1994. Outras iniciativas estão relacionadas à implantação de um novo regime de compras e contratações governamentais (2001) e a Lei da Assinatura Digital, que estabelece o marco legal para o reconhecimento das transações eletrônicas. 


\section{A experiência da Venezuela}

A história contemporânea de reforma na Venezuela teve como marco a criação, em 1984, da Comisión Presidencial para la Reforma del Estado (Copre), com o objetivo de estabelecer um Estado moderno, essencialmente democrático e eficiente, sobre o qual os postulados da Constituição adquiram plena vigência e a participação cidadã constitua-se em elemento efetivo no processo de tomada de decisões dos poderes públicos. Inicialmente, foram realizados diagnósticos e hierarquizados os problemas, a partir de um amplo processo de consulta a diversos segmentos da sociedade. Em seguida, grupos de trabalho elaboraram documentos propositivos, orientados para três áreas prioritárias: a reforma política (democratização dos partidos, reforma eleitoral e instituição da figura de prefeitos municipais), a descentralização e a reforma do Judiciário.

A preocupação com as dimensões política, econômica e administrativa nos planos de reformas esteve nos anos seguintes. No período 1994-1999, foi elaborado o IX Plan de la Nacion, que tinha como uma de suas linhas de ação básicas a reforma do Estado, incluindo, entre outros elementos, a definição de novos papéis do Estado, a reforma política, a descentralização, a participação cidadã e a busca da eficiência.

A partir de 1999, importantes mudanças caracterizaram o cenário político venezuelano. O processo de renovação constitucional colocou em destaque, mais uma vez, a necessidade de produzir importantes transformações no sistema político vigente. A descentralização também foi objeto de discussão tanto na reforma constitucional quanto nos documentos de planejamento governamental - o Plano Nacional de Desenvolvimento Regional coloca como uma das prioridades básicas a proposta de descentralização desconcentrada. No caso da nova Constituição, em que pese o reconhecimento dos importantes avanços produzidos, os mais céticos argumentam que pouco se fez em termos de reforma do Estado. O constitucionalista Allan Carías, citado em Carbonell (2001), destaca: "em definitiva, hay un nuevo y acentuado centralismo y partidismo com un acentuado presidencialismo y un nuevo militarismo constitucionalizado".

Atualmente, as questões relativas à gestão pública estão sob a liderança do vice-presidente executivo, que tem por atribuição, entre outras, coordenar a administração pública nacional, central e descentralizada funcionalmente.

Merece destaque a experiência recente de descentralização na área de educação, que tem os seguintes objetivos:

- redistribuição do poder e democratização do Estado;

- promoção de uma gestão mais eficiente e eficaz em consonância com a realidade local; e

- garantia da participação local. 


\section{A experiência da Guatemala}

Um elemento determinante do processo de redemocratização do país e, por conseguinte, básico para assegurar a legitimidade necessária ao esforço de transformação do Estado foi o Acordo de Paz celebrado em 1996, que significou um compromisso de recuperação da institucionalidade e respeito aos direitos humanos. Além disso, foi fundamental considerar, como características da realidade guatemalteca, o reconhecimento da diversidade cultural e a necessidade de fortalecer a capacidade de interlocução com as populações indígenas.

Nesse contexto, o atual governo submeteu ao Congresso da República um informe, contendo, entre outros aspectos, os que são as bases do projeto de reforma:

- a modernização e estabilização da economia, na busca da criação de condições de competitividade, visando elevar a produtividade e obter melhores indicadores de crescimento econômico com eqüidade;

- a reforma integral do Estado, uma necessidade não só para combater o atraso econômico e social, como também uma estratégia fundamental para cumprir com os acordos de paz;

- a modernização integral do setor público tanto na sua estrutura central como nos níveis desconcentrados dos departamentos e no descentralizado dos municípios, tendo como componentes centrais a modernização tecnológica e a capacitação dos recursos humanos; e

- a descentralização integral e gradual do Estado, com o objetivo de democratizar o poder público no território.

Com o objetivo de consolidar o processo de descentralização principal foco da reforma - , algumas iniciativas de natureza jurídicolegal vêm sendo empreendidas, tais como: as reformas do código municipal, da lei eleitoral e dos partidos políticos e a promulgação da Lei de Descentralização e da Lei de Participação Cidadã. Além disso, iniciativas de natureza gerencial também se destacam: a elaboração do Plano de Descentralização no âmbito da Secretaria Executiva da Presidência, a transferência de atribuições e recursos para os níveis subnacionais, a celebração de compromissos de gestão (especialmente no âmbito do Ministério da Saúde), o fortalecimento dos conselhos municipais de desenvolvimento e a criação da carreira administrativa comunal.

\section{A experiência do México}

O contexto em que se dá a experiência de reforma no México, nas duas últimas décadas, não difere substantivamente dos demais países da região. No início dos anos 80, a crise fiscal do Estado assumia proporções significativas, comprometendo a imagem internacional do país. Arellano (1997) detalha um pouco mais as características básicas do padrão vigente: 
“(...) o modelo econômico: indústrias altamente protegidas, basicamente dependentes da exportação de matéria-prima, com um elevado controle estatal, priorizando o desenvolvimento interior, protegido da competição internacional. No campo político, o sistema era formalmente democrático, com eleições livres, baseado na separação dos poderes dentro de um Estado federalista (...) na verdade dirigido por um partido dominante. Aadministração do estado era flexível, com alto nível de burocratas firmemente ligados a poderosas estruturas políticas, e subordinados a corruptos e seus esquemas (...) na verdade mal existia accountability e inexistia carreira no serviço público".

É nesse contexto que se instaura o governo de la Madrid (19821988), que focaliza sua estratégia na reforma econômica, seguindo o padrão dominante de privatizações, enxugamento da máquina pública, visando aumentar a competitividade internacional. Além disso, especial atenção é dada ao combate à corrupção. Conforme destaca Arellano, "foi definida uma meta de renovação moral da sociedade, em que a corrupção do funcionalismo foi alvo básico". Outras iniciativas apontadas pelo autor foram a descentralização e a decorrente renovação do papel dos municípios.

O período seguinte (Salinas, 1988-1994), que, para alguns analistas, não teve maiores impactos em termos de modernização da gestão pública, para Guerrero (1998) significou a reintrodução do tema serviço civil na agenda governamental, ainda que pressionado pela Organização para a Cooperação e o Desenvolvimento Econômico (OCDE). Mesmo assim, o autor recorda que os acordos celebrados com o sindicato, relativos aos trabalhadores operacionais, não foram devidamente instrumentalizados, ou foram simplesmente postergados indefinidamente. Arellano, por outro lado, destaca, no mesmo período, a manutenção dos esforços de descentralização e de simplificação administrativa, além do desenvolvimento de formas mais precisas de controle dos recursos públicos.

Entretanto, foi no governo Zedillo (1994-2000) que a reforma administrativa mexicana entrou de forma efetiva na agenda governamental, a partir do Programa de Modernização da Administração Pública 1995-2000 (Promap). Arrelano enfatiza que, pelo menos no plano formal, foi o mais ambicioso e completo programa que aconteceu na experiência recente de gestão pública no país. Segundo Guerrero, o programa apontava, no seu diagnóstico, quatro problemas básicos: limitada infra-estrutura para atender ao cidadão, excessiva centralização, deficiências em avaliação governamental e falta de profissionalização dos servidores públicos. Assim, o Promap propunha dois objetivos centrais: 
- transformar a Administração Pública Federal em organização que age eficiente e eficazmente, por meio de uma nova cultura de serviços; e

- lutar contra a corrupção e a impunidade, por meio de mecanismos preventivos e de promoção da capacidade dos recursos humanos.

Arellano lembra que o programa inaugura palavras sempre esquecidas no vocabulário da administração pública: accountability, direitos do cidadão, direitos de informação e avaliação. As principais iniciativas estavam orientadas para os seguintes subprogramas: participação e atendimento ao cidadão, descentralização administrativa, avaliação e impactos da gestão pública e profissionalização e ética para os funcionários públicos. No campo do serviço civil, vale lembrar, segundo Guerrero, que o Promap previa a concepção de um novo marco legal, que deveria estar concluído até 1997.

Outra importante iniciativa desse período, uma das pioneiras no campo do governo eletrônico, foi o desenvolvimento do Comprasnet (1996), com a finalidade de dar transparência e maior eficiência nas compras governamentais.

O atual governo, do Presidente Fox (2000-2006), que, do ponto de vista político, significou a interrupção da tradição de hegemonia do PRI, não foi ainda devidamente analisado no campo da administração pública. Entretanto, algumas iniciativas merecem ser observadas. O tema gestão pública está sob a coordenação da Secretaria de Contraloria y Desarrollo Administrativo (Secodam), no âmbito do gabinete da Presidência, e tem a seguinte missão institucional: "Eliminar os níveis de corrupção no país e dar absoluta transparência à gestão e ao desempenho das instituições e aos servidores públicos da Administração Pública Federal”.

Além disso, o governo decidiu pela criação de uma oficina para a inovação governamental, também no âmbito da Presidência, com o propósito de melhorar a capacidade de governar, para atender às expectativas da sociedade mexicana e recuperar a confiança em suas autoridades. Foram definidos os seguintes objetivos específicos:

- transformar o governo em um aparato competitivo, que alcance os objetivos planejados;

- reformar radicalmente a orientação e a capacidade de resposta de governo às necessidades da cidadania;

- romper com inércias culturais, administrativas, econômicas e políticas, realizando as mudanças necessárias; e

- recuperar o papel da liderança e a confiança dos cidadãos no governo.

Uma das iniciativas principais é o programa Governo Eletrônico, orientado para a inovação na entrega de serviços, participação cidadã e as formas de governar. Também merece destaque uma pesquisa de opinião realizada pela oficina, no sentido de conhecer os temas mais urgentes 
para a formação da agenda de inovação governamental. O resultado apontou, pela ordem de preferência, os seguintes temas: eficiência do governo, qualidade dos serviços, transparência e prestação de contas, acesso a informações, participação cidadã e mudança cultural.

\section{A experiência do Brasil}

A reforma gerencial foi introduzida no Brasil em 1995, ocasião em que foi instaurado o primeiro governo Fernando Henrique Cardoso, em contexto semelhante ao de outros países da região, caracterizado pelo aprofundamento da crise do Estado e pela emergência de reformas estruturais, prometidas durante a campanha presidencial e iniciadas alguns meses antes da posse com o Plano (real) de Estabilização Econômica. Do conjunto de reformas apresentadas como prioritárias - flexibilização de monopólios, previdência social, tributária, política etc. — destacava-se a necessidade de repensar a administração pública a partir de sinais de evidente esgotamento do modelo burocrático vigente.

Um dos primeiros movimentos de demonstração dessa prioridade foi dado quando da transformação da então Secretaria da Administração Federal (SAF) em novo ministério, que, além das funções tradicionais de gestão da função pública, assumiu o papel de coordenador do processo de reforma do aparelho do Estado. Junto desse novo ministério, denominado Ministério da Administração Federal e Reforma do Estado (Mare), foi também instalada a Câmara da Reforma doEstado, instância interministerial deliberativa sobre planos e projetos de implementação da reforma, e um Conselho da Reforma do Estado, integrado por representantes da sociedade civil, com atribuições de assessorar essa câmara nessa matéria.

Ainda em 1995, foi elaborado o Plano Diretor da Reforma do Aparelho do Estado - documento de expressão da visão estratégica e orientador dos projetos de reforma - que, a partir de diagnóstico que apontou os principais problemas da administração pública brasileira nas dimensões institucional-legal, cultural e de gestão, propôs um novo modelo conceitual, distinguindo os quatro segmentos fundamentais característicos da ação do Estado:

- núcleo estratégico - definição de leis e de políticas públicas e cobrança de seu cumprimento;

- atividades exclusivas - aquelas que são indelegáveis e que, para o seu exercício, é necessário o poder de Estado;

- atividades não-exclusivas - aquelas de alta relevância em que o Estado atua, simultaneamente com outras organizações privadas e do terceiro setor, na prestação de serviços sociais; e

- produção de bens e serviços ao mercado - que corresponde ao setor de infra-estrutura em que atuam as empresas e em que há, portanto, tendências à privatização. 
As principais iniciativas, nesse primeiro período, foram orientadas para a revisão do marco legal (reforma constitucional e da legislação corrente), a proposição de uma nova arquitetura organizacional (agências reguladoras, executivas e organizações sociais), a adoção de instrumentos gerenciais inovadores (contratos de gestão, programas de inovação e de qualidade na administração pública) e a valorização do servidor (nova política de recursos humanos, fortalecimento de carreiras estratégicas, revisão da política de remuneração, realização de concursos públicos e intensificação da capacitação de funcionários, visando promover a mudança cultural).

Em 1998, foi extinto o Mare e as suas funções foram absorvidas pelo Ministério do Planejamento, Orçamento e Gestão, em esforço de integração dos principais instrumentos de gerenciamento governamental: planejamento, orçamento e gestão. A esse respeito, Bresser Pereira (2002) argumenta que o desafio seguinte — o de implementação — não poderia ser atribuído a um ministério pequeno, desprovido de poder Executivo, daí a recomendação feita (inspirada na experiência chilena) de passar a responsabilidade ao novo ministério. Nesse novo contexto, o planejamento governamental, a partir do lançamento do Plano Plurianual (PPA 2000-2003), mais conhecido como Avança Brasil, assumiu papel protagonista. Esse plano foi elaborado com base em diretrizes estratégicas do presidente da República, destinadas a consolidar a estabilidade econômica com crescimento sustentado. Além disso, foi adotado um novo conceito de programa, segundo o qual as ações e os recursos do governo são organizados de acordo com os objetivos a serem atingidos, e foi instituída a figura do gerente de programa, como elemento central no processo. Ainda, no âmbito federal, merecem ser destacadas as iniciativas de intensificação do uso da tecnologia da informação orientadas para a melhoria do atendimento ao cidadão no relacionamento com o setor privado, a transparência e modernização da gestão interna (governo eletrônico, Comprasnet, Receitanet, quiosques, rede governo, sistemas corporativos de gestão).

Finalmente, vale ressaltar as iniciativas de reforma realizadas nos âmbitos estadual e municipal. No campo da recuperação da capacidade financeira, dentro do novo marco de responsabilidade fiscal, o Programa Nacional de Apoio à Administração Fiscal (PNAFE) vem cumprindo importante papel de melhor aparelhar as máquinas de administração tributária e financeira dos Estados brasileiros — agora estendido aos municípios —, a partir da adoção de um modelo inovador, estruturado em rede (Ministério da Fazenda e Secretarias Estaduais de Finanças), que, além de realizar atividades de apoio financeiro e assistência técnica, trabalha a perspectiva educacional com iniciativas de sensibilização da sociedade para a conscientização fiscal (via campanhas e projetos nas escolas). Também são relevantes as iniciativas estaduais orientadas para o atendimento 
integrado ao cidadão (One Stop Shopping), que teve, como experiência pioneira, o Serviço de Atendimento ao Cidadão (SAC), na Bahia, hoje implantado em outras unidades da Federação.

\section{Os desafios da reforma gerencial, à guisa de conclusão: em busca de elementos para configurar uma nova agenda}

O debate sobre a administração pública tem ocupado importante espaço na agenda internacional, nos fóruns de discussão e nas diversas publicações especializadas sobre o contexto contemporâneo de transformação do Estado e da sociedade. Na verdade, isto não significa nenhuma novidade: faz-se reforma da administração pública desde que ela existe. Também é certo que o debate sobre a gestão pública se confunde, na maior parte dos casos, com o debate sobre o Estado, embora nem sempre seguindo o mesmo ritmo. Bresser Pereira (2002) comenta, a propósito, que:

“(...) Estes são avanços políticos bem conhecidos que ocorrem na sociedade civil e nos ajustes institucionais. Eles devem, a princípio, ser combinados com respectivos desenvolvimentos na organização do aparelho do Estado, mas o que vemos é que mudanças organizacionais e administrativas tendem a mover em um ritmo mais lento do que as mudanças em níveis político e institucional. Realmente, enquanto pude verificar cinco formas de regimes políticos, desde que os Estados nacionais modernos emergiram - o absoluto, o liberal, o liberal-democrático, o democráticosocial e o emergente Estado liberal social —, posso somente detectar três formas de administração do Estado: patrimonial, burocrática e a emergente administração gerencial ou nova gestão pública".

Talvez isso possa significar a prevalência da tendência gerencialista na administração pública por algum tempo. Ou será que, desta vez, transformações no contexto provocarão uma aceleração nos movimentos de mudança do padrão de gerência pública?

Voltando um pouco no tempo e tentando reconstruir o cenário que fez emergir o modelo da NGP, os principais elementos que motivaram esse movimento ainda estão presentes na realidade latino-americana: crise fiscal, persistência da cultura burocrática em meio a práticas patrimonialistas e profundo déficit de desempenho em termos de quantidade e qualidade na prestação de serviços públicos, dentre outros. Entretanto, há sinais de novos temas emergentes ou de antigos temas que emergem de forma diferente. Um deles, certamente, é a questão do desenvolvimento, agora posto em outra perspectiva, que inclui a idéia

força de sustentabilidade e necessidade de alinhamento com outra idéia 
força, que é a estabilidade econômica, política, institucional e social, em um mundo globalizado. O tema não é novo e já foi tratado pela administração pública burocrática, à época do Estado Nacional e do bem-estar, nos anos 50 e 60, com nome e sobrenome: administração para o desenvolvimento. E agora? Que novos atributos precisam ser incorporados à gerência pública, para que ela seja um efetivo instrumento desse neodesenvolvimentismo?

Também não se pode desconsiderar outro tema emergente na agenda do Estado contemporâneo: a questão da segurança. Principalmente, depois dos episódios recentes nos Estados Unidos, na Colômbia, no Rio de Janeiro etc. Outra vez um tema recorrente, mas que surge a partir de uma nova perspectiva, colocando um desafio adicional. É perceptível que há tradição na realidade latino-americana quanto ao trato dessa questão, mas em contexto diferente. É válido ressaltar que enfrentar os problemas de segurança em contexto autoritário difere de enfrentar o mesmo problema em regime democrático. E isso também exigirá a incorporação de novos atributos nos modelos de gerenciamento público.

Concluindo, ainda que com mais perguntas do que respostas, o debate contemporâneo sobre as questões de desenvolvimento da sociedade, sobre as questões de Estado e sobre as questões de gestão pública, parecem reafirmar-se alguns dos princípios básicos da agenda atual, tais como: a focalização no cidadão, a transparência, o controle social, a conscientização da responsabilidade fiscal, a orientação da gestão para resultados, a ética e a profissionalização do servidor público. Dessa forma, o grande desafio é o de assegurar a irreversibilidade do processo de transformação, a partir do fortalecimento das iniciativas bem-sucedidas e do realinhamento que se fizer necessário para a incorporação dos temas emergentes. Isso vai exigir:

- reorientação na estratégia de implementação do modelo gerencial, que não é único, levando em consideração as características locais, inclusive aspectos de multiculturalidade, evitando, dessa forma, a pura importação de práticas adotadas em realidades distintas;

- identificação de novos perfis profissionais desejados e desenvolvimento de mecanismos inovadores de capacitação para adequação dos perfis principalmente para as lideranças;

- construção de uma rede de cooperação entre os países da região, visando ao intercâmbio de experiências e práticas inovadoras de gestão;

- revisão do marco legal, notadamente em aspectos ligados à profissionalização da função pública, controle social e descentralização; e

- intensificação do uso de tecnologias de informação orientadas para transparência na gestão, melhoria nas relações com o cidadão e modernização administrativa. 
Este artigo é uma adaptação feita a partir da versão original do Relatório Final do Curso Internacional sobre a Reforma Gerencial, realizado na ENAP Escola Nacional de Administração Pública, no período de 18 de fevereiro de 2002 a 1o de março de 2002, no contexto do Escola Ibero-Americana de Governo e Políticas Públicas (IBERGOP). Participaram 22 servidores públicos, representantes de 12 países, a saber: Argentina, Brasil, Chile, Espanha, Guatemala, México, Nicarágua, Panamá, Peru, Portugal, Uruguai e Venezuela. O autor foi relator do curso e acrescentou elementos adicionais ao texto original, visando dar-lhe maior amplitude.

2 Os relatos de experiências apresentados, a seguir, não se conformam com o que formalmente se conhece por estudo de casos nem têm a pretensão de realizar uma análise comparativa. Isto, certamente, exigiria maior aprofundamento investigativo, apoiado na utilização de metodologias científicas.

\section{Referências bibliográficas}

Arellano, David G. (1997), “Avanços desiguais e intenções indefinidas: a reforma do Estado no México e a estratégia de gerenciamento”. Revista do Serviço Público, Brasília, ano $48, n^{-} 3$, dezembro.

BERRETTA, Nora. (2000), Modernizacion administrativa y la gestion pública em Uruguay. Estudio de caso. Universidad de Chile e Banco Interamericano de Desarrollo, novembro.

Bresser Pereira, Luiz Carlos. (2002), "Reforma da nova gestão pública: agora na agenda da América Latina, no entanto ...”. Revista do Serviço Público, Brasília, ano 53, no 1, jan.-mar.

Cabonell, M., Concha Cantu, H., Valades, D. (2001), "Estrategias y propuestas para la reforma del Estado". Instituto de investigaciones jurídicas, serie g: estudios doctrinales, no 188, México: UNAM.

Clad. (1998), "Uma nova gestão pública para América Latina”. Documento do CLAD, outubro.

CoBAs, Eduardo. (1998), "La reforma administrativa del Estado Uruguayo". Apresentado no seminário Presente y futuro de los procesos de reforma del Estado. Montevidéo, dezembro.

GHIo, José Maria. (2000), Reforma del Estado y modernización administrativa - Argentina 1989-1999. Estudio de caso. Universidad de Chile e Banco Interamericano de Desarrollo, novembro.

Guerrero, Juan Pablo. (1998), Um estudio de caso de la reforma administrativa em México: los dilemas de la instauración de um servicio civil a nivel federal. México: Centro de Investigación y Docencia Económicas.

OrRego, Cláudio. (1998), Modernizacion del Estado y la gestion pública em Chile: balance y desafios. Apresentado no seminário Presente y futuro de los procesos de reforma del 
RAmió, Carles. (2001), "Los problemas de la implementacion de la nueva gestión pública em las administraciones públicas latinas: modelo de estado y cultura institucional". Revista Reforma e Democracia CLAD, outubro.

SHEPHERD, Geoffrey. (1998), El desafio de la reforma administrativa em América Latina. Apresentado no III Congresso Internacional do CLAD, Madrid.

\section{Sites consultados:}

http://www.vicepresidencia.gob.ni/cerap.html (Nicarágua)

http://www.modernizacion.cl (Chile)

http://www.segpres.cl/index2.html (Chile)

http://cepre.opp.gub.uy/index2.htm (Uruguai)

http://www.sfp.gov.ar/ (Argentina)

http://www.secodam.gob.mx//index1.html (México)

http://innova.presidencia.gob.mx/index 2.shtml (México)

http://www.segeplan.gob.gt/spanish/publications/index.html (Guatemala)

http://www.copri.org/ (Peru)

http://www.perugobierno.gob.pe/ (Peru)

http://www.venezuela.gov.ve/ns/index.htm (Venezuela)

http://www.mpd.gov.ve/ixplan/ixplan.htm (Venezuela)

http://www.fazenda.gov.br/ucp/pnafe (Brasil)

http://www.planejamento.gov.br (Brasil) 
Revista do

Serviço

Público

Ano 53

Número 4

Out-Dez 2002

Caio Marini é

assessor da

direção do

Serpro,

professor

colaborador

na FGV, ENAP

e ESAF

Contato:

caio.marini@

serpro.gov.br

\section{O contexto contemporâneo da administração pública na América Latina Caio Marini}

O artigo é uma adaptação feita a partir da versão original do Relatório Final do Curso Internacional sobre a Reforma Gerencial, realizado na ENAP Escola Nacional de Administração Pública, em fevereiro de 2002, no contexto da Escola Ibero-Americana de Governo e Políticas Públicas (IBERGOP). Parte de uma reflexão inicial sobre a reforma gerencial no contexto de transformação do Estado, destacando especificidades da realidade latino-americana, tomando como referência o documento aprovado, em 1998, pelo Conselho Científico do Centro Latino-Americano de Administração para o Desenvolvimento (CLAD), que estabeleceu as bases da reforma na região. Em seguida, é apresentado um balanço a partir do exame de algumas experiências nacionais selecionadas. Finalmente, à guisa de conclusão, são propostos alguns temas emergentes, visando à construção de uma nova agenda para a reforma da administração pública na América Latina.

\section{El contexto contemporáneo de la administración pública en América Latina Caio Marini}

El texto presenta una adaptación de la versión original del Informe Final del Curso Internacional sobre la Reforma Gerencial, realizado en la ENAP Escuela Nacional de Administración Pública, en febrero de 2002, en el marco del Escuela Ibero-Americana de Gobierno y Politicas Publicas (IBERGOP). Tras una reflexion sobre la reforma gerencial en el marco de la transformación del Estado, el autor destaca las especificidades de la realidad latino-americana, tomando como referencia el documento aprobado, en 1998, por el Consejo Cientifico del Centro Latiniamericano de Administración para el Desarrollo (CLAD), que estableció las diretrices de la reforma en la región. Luego, se presenta un balance a partir de algunas experiencias nacionales selecionadas. A modo de conclusión, se proponen algunos temas emergentes con el propósito de construir una nueva agenda para la reforma de la administración pública en América Latina.

\section{Contemporary scene of the public administration in Latin America Caio Marini}

The article is an adaptation of the original version of the Final Report of the International Course of Managerial Renovation, held in ENAP Escola Nacional de Administração Pública (National School of Public Administration), in February 2002, with Escola Ibero-americana de Governo e Políticas Públicas - IBERGOP (Iberian-American School of Government and Public Politics). It results from an initial reflection on the managerial renovation as a transformation of the State, emphasizing particularities of the Latin-American reality and taking as a reference the document approved in 1998 by the Scientific Council of the LatinAmerican Center for Development Administration (CLAD), which establishes the bases for the renovation in the region. A balance elaborated through the examination of some selected national experiences is presented below. Finally, some emerging terms are proposed for the construction of a new agenda for the public. 